DOI: https://doi.org/10.47405/mjssh.v7i1.1249

\begin{tabular}{|c|c|}
\hline 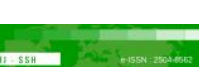 & Malaysian Journal of Social Sciences and Humanities (MJSSH) \\
\hline Malaysian Journal of & Volume 7, Issue 1, January 2022 \\
\hline (MJ. SSH) & e-ISSN : 2504-8562 \\
\hline & $\begin{array}{l}\text { Journal home page: } \\
\text { www.msocialsciences.com }\end{array}$ \\
\hline
\end{tabular}

\title{
Penggunaan Bahan Bantu Mengajar Guru Pendidikan Khas dalam Meningkatkan Kemahiran Matematik Operasi Darab
}

\author{
Nur Hana Kamarudin', Khairul Farhah Khairuddin', Ahmad Zamri Mansor1 \\ 1Fakulti Pendidikan, Universiti Kebangsaan Malaysia (UKM), Malaysia \\ Correspondence: Khairul Farhah Khairuddin (kfk@ukm.edu.my)
}

\begin{abstract}
Abstrak
Kajian ini dijalankan bagi melihat penggunaan bahan bantu mengajar guru pendidikan khas pembelajaran dalam meningkatkan kemahiran matematik operasi darab. Kajian ini juga bertujuan untuk meneroka amalan guru Pendidikan Khas pembelajaran dalam penggunaan bahan bantu mengajar, jenis-jenis bahan bantu mengajar bagi meningkat kemahiran matematik operasi darab. Kajian ini menggunakan kajian kes yang terdiri daripada 5 orang guru Pendidikan khas pembelajaran yang mengajar mata pelajaran matematik dari beberapa buah sekolah di daerah Pudu, Kuala Lumpur. Kajian ini menggunakan dua instrumen kajian yang terdiri daripada temu bual dan analisis dokumen. Bagi menilai kesahan dan kebolehpercayaan, triangulasi data digunakan bagi mengukuhkan data kajian yang diperolehi agar ia tidak boleh diragui ketepatan dan keteguhan data yang diperolehi. Hasil daripada dapatan kajian menunjukkan bahawa amalan guru dalam penggunaan bahan bantu mengajar mempengaruhi peningkatan dalam kemahiran matematik operasi darab. Amalan guru dalam kesediaan sebelum bermulanya sesi PdPc, BBM sebagai pemudah cara, mengenal pasti tahap penguasaan serta jenis BBM yang digunakan merupakan faktor yang mampu meningkatkan kemahiran matematik operasi darab bagi murid-murid khususnya MBK pembelajaran. Penggunaan bahan bantu mengajar yang menarik dan kreatif dapat menarik minat MBK pembelajaran dalam menguasai mata pelajaran matematik terutama dalam operasi darab.
\end{abstract}

Kata kunci: bahan bantu mengajar, kefahaman, MBK Pembelajaran, kemahiran matematik, operasi darab

\section{The Use of Teaching Aids for Special Education Teachers in Improving Multiplication Operations Mathematical Skills}

\begin{abstract}
This study aimed to investigate the use of teaching aids for special education teachers in improving multiplication skills. This study also aims to investigate the practice of Special Education teachers learning in the use of teaching aids and the different types of teaching aids used to improve multiplication skills. This study employs a case study of five special education teachers who teach mathematics subjects at various schools in the Pudu district of Kuala Lumpur. Interviews and document analysis were used as research tools in this study. Data triangulation is used to assess the validity and reliability to strengthen the study data obtained, not to question the accuracy and robustness of the data obtained. The study's findings indicate that teachers' use of teaching aids improves mathematical skills in multiplication operations. Teachers' preparation before the start of the PdPc session, BBM as a facilitator, identifying the level of mastery, and the type of BBM used are
\end{abstract}


factors that can improve students' mathematical skills of multiplication operations, particularly MBK learning. The use of engaging and creative teaching aids can pique the interest of MBK students in mastering the subject of mathematics, particularly multiplication operations.

Keywords: Teaching aids, comprehension, MBK Learning, mathematical skills, multiplication operations

\section{Pengenalan}

Pendaraban atau operasi darab merupakan salah satu kemahiran asas matematik yang mempunyai aras pembelajaran yang tinggi. Sepanjang persekolahan di sekolah rendah dan menengah, murid-murid dibimbing untuk mengembangkan dan mahir dalam kemahiran mengira berdasarkan kemahiran kuantitatif iaitu mengikut langkah yang logik (KPM, 2015). Kurikulum Standard Sekolah Menengah Pendidikan Khas (KSSMPK) digubal secara berperingkat-peringkat dan bermula pada tahun 2017 adalah secara dasarnya menitik beratkan pendidikan yang bersesuaian dengan keupayaan murid MBK dari segi kognitif dan keupayaan MBK untuk mengikuti mata pelajaran kemahiran. KSSMPK dirancang untuk membolehkan murid mengaplikasikan apa yang mereka pelajari di dalam kelas untuk kehidupan seharian mereka. Kurikulum ini juga melengkapkan Murid Berkeperluan Khas (MBK) Pembelajaran dengan pendidikan yang sebaik mungkin agar mereka dibentuk menjadi insan yang seimbang, berdikari dan berjaya dalam kehidupan mereka. Selain daripada itu, MBK juga tidak ketinggalan menyumbang sebagai modal insan yang perlu diberi perhatian agar mereka mampu untuk hidup berdikari dan menyumbang kepada pembangunan negara khususnya,

Berdasarkan dengan keadaan ini penguasaan dan kefahaman tentang konsep asas matematik terutama bagi operasi darab amat diperlukan dalam kehidupan seharian. Perkembangan mental dan fizikal setiap murid adalah berbeza antara individu. Pendidikan untuk semua yang yang diperkenalkan oleh Kementerian Pendidikan Malaysia (KPM) memberikan peluang dan hak kepada semua murid untuk mendapat pendidikan tanpa mengira perkembangan intelek murid mahupun latar belakang sosial mereka. Hal ini membolehkan, murid yang mempunyai masalah pembelajaran mendapat hak dan peluang yang sama seperti murid-murid tipikal yang lain. Walau bagaimanapun, murid bermasalah pembelajaran sering menghadapi masalah dalam proses pembelajaran terutama dalam mata pelajaran matematik. Mereka sering kali tidak dapat menguasai sepenuhnya pengiraan asas matematik terutama operasi darab. Melalui kaedah dan strategi yang diguna pakai oleh guru, sedikit sebanyak dapat membantu dan seterusnya dapat murid menyelesaikan masalah matematik dengan baik (KPM, 2015).

Kajian yang dijalankan ini dapat memberikan panduan serta idea untuk memilih bahan bantu yang sesuai dengan tahap kognitif Murid Berkeperluan Khas (MBK) Pembelajaran di sekolah, terutama bagi murid Program Pendidikan Khas Integrasi (PPKI). Objektif kajian ini dijalankan adalah bertujuan untuk meneroka amalan penggunaan bahan bantu mengajar guru pendidikan khas masalah pembelajaran dalam kemahiran matematik operasi darab serta meneroka jenis bahan bantu mengajar yang digunakan dalam penggunaan bahan bantu mengajar kemahiran matematik operasi darab. Dalam kajian ini, guru matematik yang mengajar di aliran pendidikan khas masalah pembelajaran yang menyertai sesi temu bual dan di analisis dokumen. Tahap kefahaman dan penguasaan murid dalam sesuatu topik pengajaran adalah lebih berkesan sekiranya dibantu dengan penggunaan bahan bantu mengajar . Oleh itu guru perlu berusaha untuk memenuhi keperluan dan kebolehan murid-murid dalam memilih bahan bantu mengajar dari pelbagai sumber. Pemilihan bahan bantu mengajar yang sesuai daripada pelbagai sumber mampu menarik minat seterusnya meningkatkan kefahaman murid-murid tentang sesuatu topik.

\section{Sorotan Literatur}

Penggunaan bahan bantu mengajar dalam proses pengajaran dan pembelajaran merupakan salah satu faktor yang penting dalam mencapai objektif pengajaran dan pembelajaran. Kementerian Pendidikan 
Malaysia (KPM) telah berusaha meningkatkan mutu pendidikan di Malaysia setanding dengan negaranegara maju dalam menghadapi dunia globalisasi yang semakin mencabar. Menurut Mohd Zuri dan Aznan (2012) konsep pembelajaran matematik yang melalui proses penghafalan dan penyampaian ilmu daripada guru kepada murid adalah kurang berkesan. Ini adalah kerana kaedah yang digunakan ini, membolehkan murid menyelesaikan soalan-soalan ujian tetapi mereka gagal untuk mengaplikasikan kemahiran yang telah dipelajari di luar bilik darjah. Seterusnya murid akan mengalami kesulitan dalam proses pengiraan yang banyak digunakan dalam aktiviti seharian. Sehubungan dengan itu, murid yang mengalami masalah pembelajaran kurang sesuai mengikuti pembelajaran secara formal yang memenuhi kurikulum kebangsaan.

Majoriti murid bergelut dengan pembelajaran matematik kerana konsep matematik yang abstrak. Untuk mencapai hasil pembelajaran yang optimum, murid mesti memperoleh pengalaman nyata dengan konsep matematik yang abstrak dan manipulasi (Mohd Rino, 2019). Penggunaan bahan bantu mengajar yang menarik serta bermakna mampu memberikan murid keseronokan semasa sesi pembelajaran. Selain daripada itu, perubahan tingkah laku (introvert) seseorang murid yang tidak meminati mata pelajaran matematik boleh diubah menjadi lebih berminat dan seronok (Mohd Rino, 2019). Tambahan pula dengan penggunaan warna yang bersesuaian dengan bahan bantu yang digunakan oleh guru dalam membangunkan bahan bantu mengajar. Pembinaan bahan bantu mengajar I-KOAM yang dibangunkan oleh Mohd Rino (2019) yang menghubung jalinkan rangsangan motor halus iaitu menggunakan bahan maujud seperti guli, penggunaan audio iaitu bunyi sensor serta menggunakan mentol led yang menyala sebagai rangsangan penglihatan. Pembinaan bahan bantu mengajar seperti ini mampu menarik minat murid seterusnya merangsang murid untuk mencuba BBM ini untuk menyelesaikan soalan matematik yang lebih mencabar.

Gabungan diantara suara, warna dan gambar menjadikan bahan bantu mengajar yang berasaskan teknologi maklumat dan komunikasi lebih memberi kesan kepada murid-murid. Dalam kajian (Hanifah et al., 2020) Penggunaan bahan bantu mengajar berasaskan multimedia dalam mata pelajaran geografi, telah memberi impak yang besar kepada proses pengajaran dan pembelajaran di dalam kelas. Penggunaan elemen dan reka bentuk bagi bahan bantu mengajar ini mampu menarik minat dan kefahaman murid seterusnya menjadikan sesi pengajaran dan pembelajaran itu menjadi menarik dan menyeronokkan.

Terdapat dua jenis bahan bantu mengajar menurut Jasmi et al. (2011). Buku teks, skrin LCD, komputer riba, kertas mahjong, kertas edaran, buku rujukan dan modul adalah contoh bahan bantu pengajaran berbentuk pola. Bahan yang bukan berbentuk pola adalah seperti carta, kaset dan bahan lain yang sedia ada ialah pilihan lain untuk bilik darjah yang kekurangan ruang atau sumber untuk membeli alat bantu mengajar khusus. Alat bantu mengajar elektronik dan bukan elektronik. Menurut Musa dan Mohamad (2014), Terdapat dua kategori yang berbeza. Bahan pengajaran yang menggunakan media elektronik termasuk televisyen, projektor, slaid dan radio serta filem dan bahan bantuan komputer. Kad imbasan, model, majalah, buku nota dan gambar yang berkaitan dengan pelajaran adalah contoh bahan pengajaran bukan elektronik.

Walau bagaimanapun, terdapat beberapa kajian yang membuktikan penggunaan multimedia dalam pengajaran dan pembelajaran tidak bersesuaian dengan beberapa mata pelajaran seperti contoh dalam kajian Jeffery (2018), yang menyatakan penggunaan bahan bantu mengajar yang berbentuk teknologi maklumat kurang popular di kalangan guru-guru bahasa Melayu. Kajian yang dijalankan oleh Hayazi (2008), menunjukkan perkaitan di antara kemudahan, sikap dan kemahiran teknologi maklumat di kalangan guru-guru sekolah teknik menunjukkan berada di tahap sederhana. Dapatan yang diperolehi, menunjukkan persediaan guru bagi melaksanakan sesi pengajaran dan pembelajaran dengan menggunakan komputer berada di peringkat yang awal.

\section{Kaedah Kajian}

Kajian yang dijalankan ini adalah berbentuk kualitatif yang menggunakan kajian kes bagi melihat penggunaan bahan bantu mengajar guru pendidikan khas masalah pembelajaran dalam meningkatkan 
kefahaman kemahiran matematik operasi darab di kalangan guru mata pelajaran matematik Program Pendidikan Khas Integrasi (PPKI) di Daerah Pudu, Kuala Lumpur. Faktor pemilihan peserta kajian yang terdiri daripada kerana mereka merupakan insan yang dekat dengan murid dan lebih memahami serta mengetahui tahap kognitif murid. Terdapat empat Sekolah Menengah Kebangsaan yang mempunyai Program Pendidikan Khas Integrasi (PPKI) dipilih, yang berkaitan dengan kajian ini. Dalam kajian ini, pengkaji menggunakan kaedah sesi temu bual dan analisis dokumen bersama guru matematik untuk memberi pengukuhan terhadap dapatan kajian. Kaedah ini digunakan untuk mengumpul semua maklumat yang diperlukan dan berkaitan dengan objektif utama kajian. Triangulasi data ialah teknik mengumpul data kualitatif, yang kemudiannya dianalisis untuk meningkatkan kesahan dan kebolehpercayaan maklumat yang dikumpulkan. Kesahan yang boleh didefinisikan sebagai keupayaan bagi mengukur instrumen yang sebenar dan kebolehpercayaan merupakan keupayaan bagi pemerolehan data yang serupa apabila pengukuran dibuat (Chua, 2014).

Data yang diperolehi memerlukan semakan bagi memastikan data-data yang dikumpul terdapat kesahan dan kebolehpercayaan yang tinggi serta tidak meragukan. Menurut Chua (2014), pula menyatakan bahawa kesahan didefinisikan sebagai keupayaan untuk mengukur instrumen yang sebenar-benarnya manakala kebolehpercayaan pula bermaksud keupayaan dalam pemerolehan yang serupa apabila pengukuran dilakukan. Oleh itu, bagi menentukan kesahan dan kebolehpercayaan, pengkajian menggunakan kaedah triangulasi data. Kajian ini menganalisis data-data daripada sesi temu bual yang telah dilakukan penyelidik serta diterima bagi memenuhi kehendak kajian, seterusnya data yang diperolehi akan dianalisis secara manual. Hasil daripada dapatan temu bual telah direkodkan dan kemudiannya ditranskripsikan supaya dialog temu bual jelas berkaitan dengan penggunaan bahan bantu mengajar bagi meningkatkan kemahiran matematik operasi darab dalam kalangan guru pendidikan khas pembelajaran.

\section{Dapatan Kajian}

Data kajian diperoleh melalui temu bual yang telah dijalankan terhadap lima orang peserta kajian iaitu guru Pendidikan Khas Pembelajaran yang mengajar mata pelajaran matematik di empat buah Sekolah Menengah (PPKI) di daerah Pudu, Kuala Lumpur. Setiap peserta kajian di kodkan sebagai PKG1, PKG2, PKG3, PKG4 dan PKG5. Kelima-lima peserta kajian terdiri daripada guru perempuan. Berikut merupakan jadual bagi dapatan demografi peserta kajian:

Jadual 1. Profil demografi peserta kajian

\begin{tabular}{llr}
\hline Profil peserta kajian & Demografi & Jumlah \\
\hline Jantina & Lelaki & 0 \\
Umur & Perempuan & 5 \\
& $26-35$ tahun & 1 \\
\multirow{3}{*}{ Kelulusan tertinggi } & $36-45$ tahun & 3 \\
& 46 tahun ke atas & 1 \\
& Sijil Perguruan & 0 \\
& Diploma Pendidikan & 0 \\
Bidang pengkhususan & Ijazah Pendidikan & 5 \\
& Sarjana Pendidikan & 0 \\
& Pendidikan Khas Masalah & 3 \\
Pengalaman mengajar matematik & Pembelajaran & 1 \\
& Linguistik & 1 \\
& Ekonomi & 0 \\
& Kurang dari 3 tahun & 4 \\
& $4-10$ tahun & 1 \\
& $11-15$ tahun & 0 \\
& $16-20$ tahun & 0 \\
\hline
\end{tabular}


DOI: https://doi.org/10.47405/mjssh.v7i1.1249

Jadual 1 menunjukkan profil demografi peserta kajian yang melibatkan lima orang guru matematik PPKI perempuan yang terdiri daripada seorang guru yang 26 hingga ke 35 tahun, tiga orang guru yang berumur 36 hingga 40 tahun dan seorang guru yang berumur 46 tahun ke atas. Dari aspek pendidikan kelima-lima peserta kajian mempunyai Ijazah Pendidikan yang terdiri daripada tiga guru yang mengambil pengkhususan dalam Pendidikan Khas Masalah Pembelajaran, seorang guru yang mengikuti linguistik dan seorang guru yang memiliki pengkhususan dalam bidang ekonomi. Seterusnya pengalaman yang dimiliki oleh peserta kajian dalam mengajar mata pelajaran matematik ialah empat orang yang mempunyai pengalaman dari 4 hingga 10 tahun dan seorang guru yang mempunyai pengalaman 11 hingga 15 tahun. Kelima-lima peserta kajian ini mempunyai kefahaman yang jelas tentang penggunaan bahan bantu mengajar.

\section{Meneroka amalan guru dalam penggunaan bahan bantu mengajar}

Analisis bagi objektif kajian 1, iaitu meneroka amalan guru dalam penggunaan bahan bantu mengajar guru pendidikan khas dalam meningkatkan kemahiran matematik operasi darab serta tahap kefahaman guru mengenai bahan bantu mengajar adalah bertujuan untuk melihat sejauh mana guru mengetahui pengunaan bahan bantu mengajar dalam sesi pengajaran dan pembelajaran.

\section{Bahan bantu mengajar sebagai pemudah cara}

Tiga daripada peserta kajian menyatakan bahawa penggunaan bahan bantu mengajar merupakan bahan atau alat pemudah cara bagi menyampaikan pengajaran kepada murid. Hal ini dapat ditunjukkan melalui transkripsi temu bual yang dijalankan seperti berikut :

"Mengikut kefahaman saya bahan bantu mengajar adalah alat pemudah cara bagi guru untuk menyampaikan maklumat kepada murid dengan lebih berkesan”. (PKG 2)

"Bagi saya, bahan bantu mengajar adalah bahan untuk bantu semasa sesi pengajaran dan memudahkan PdP”. (PKG 3)

"BBM adalah bahan yang digunakan oleh guru untuk memudahkan PdPc yang dijalankan". (PKG 5)

Selain daripada itu, PKG 1 menyatakan bahan bantu mengajar sebagai satu kelengkapan kepada guru bagi digunakan semasa sesi pengajaran dan pembelajaran. Hal ini ditunjukkan didalam transkripsi berikut :

"BBM adalah segala kelengkapan yang digunakan untuk membantu guru dan murid dalam PdPc yang terdiri daripada bahan elektronik dan bahan bukan elektronik”. (PKG 1)

PKG 4 turut menyatakan bahan bantu mengajar yang bersesuaian dapat membantu murid memahami pembelajaran dengan lebih jelas terutama dalam pengunaan kad imbas dan video pengajaran. Ini dinyatakan di dalam transkripsi :

"BBM yang baik dapat membantu murid memahami sesuatu pembelajaran itu dengan lebih jelas dan terang. Saya biasa menggunakan Flash card dan video bagi memberikan lebih kefahaman kepada murid saya". (PKG 4)

Penggunaan bahan bantu mengajar sebagai bahan atau alat pemudah cara disokong dengan kajian yang dilakukan oleh Norfarizah dan Mohd Zazril (2019), Noor Azimah (2019). Selain daripada pemudah cara, bahan bantu mengajar mampu menarik minat murid terutama Murid Berkeperluan Khas (MBK) pembelajaran serta mengikuti sesi pengajaran dan pembelajaran dengan lebih berkesan dan berfokus. 
Pengunaan bahan bantu mengajar bagi murid-murid MBK pembelajaran memberikan kesan yang sangat baik dalam memahami sesuatu perkara.

\section{Kesediaan guru sebelum sesi pengajaran}

Analisis Objektif 1 bagi amalan guru dalam penggunaan bahan bantu mengajar bagi subtema pertama iaitu kesediaan guru sebelum memulakan sesi pengajaran adalah tinggi kerana kelima-lima peserta kajian melakukan perancangan yang rapi sebelum kelas bermula serta bersedia dengan bahan bantu mengajar semasa pengajaran operasi darab.

"Kebiasaanya saya membuat persediaan sehari sebelum aktiviti pengajaran dijalankan, sekiranya saya mengajar operasi darab saya akan pastikan buku sifir, kad nombor ataupun bahan yang boleh dilihat, dipegang. Didengar atau senang kata menggunakan pelbagai deria yang ada pada murid". (PKG 1)

"Saya akan membuat perancangan pengajaran saya diantara satu ke tiga hari atau lebih. Ini bagi memastikan saya bersedia semasa sesi PdPc dijalankan. Penggunaan bahan maujud sentiasa menjadi keutamaan saya". (PKG 2)

"Biasanya saya akan merancang seminggu sebelum pengajaran saya. Saya akan membuat latihan secara ansur maju dari senang kepada susah dan dimulakan dengan bentuk lazim dan dari situ saya akan melihat pemahaman murid terhadap operasi darab serta saya akan memberikan penerangan kepada murid bagaimana proses itu berlaku”. (PKG 3)

"saya akan mengambil lebih kurang masa dalam dua hari untuk merancang pengajaran saya. Saya menggunakan jadual sistem pantas darab untuk memberi kefahaman kepada murid". (PKG 4)

"Sehari sebelum kelas dijalankan saya akan membuat beberapa perancangan pengajaran saya. Saya akan menggunakan bahan yang terdapat didalam kelas atau sekitar murid. Adakalanya saya menggunakan blok kayu atau guli. (PKG 5)

Daripada analisis trankripsi temu bual yang telah dijalankan keatas peserta kajian, perancangan yang rapi bagi setiap sesi pengajaran dan pembelajaran sangat penting bagi menjadikan pengajaran dan pemudah cara $(\mathrm{PdPc})$ yang dijalankan mencapai objektif dan seterusnya memberikan kefahaman dan keseronokan dalam sesi pengajaran dan pembelajaran di dalam kelas.

\section{Tahap penguasaan murid}

Bagi subtema kedua bagi amalan guru dalam penggunaan bantu mengajar mendapati tahap penguasaan seseorang murid mempengaruhi penentuan dalam penggunaan bahan bantu mengajar. Hasil daripada analisis transkripsi temu bual PKG 1, PKG 2, PKG 4 dan PKG 5 menyentuh tentang tahap penguasaan murid :

"BBM yang digunakan perlu dirancang dan selari dengan perancangan yang telah dibuat dan tahap kebolehan murid juga diambil kira. Kepelbagaian penggunaan bahan bantu mengajar mampu menarik minat murid.”. (PKG 1)

"Mengikut kesesuaian...sekiranya perlu, guru akan mencari idea baharu yang sesuai dengan tahap kefahaman murid. BBM yang saya gunakan mengikut tahap MBK semasa saya menjalankan pdpc.”. (PKG 2)

"Saya akan melihat kepada tahap pengguasaan murid, sekiranya murid masih tidak memahami konsep asas darab saya akan menggunaka bahan yang mudah difahami murid". (PKG 4) 
"Saya akan gunakan BBM mengikut kelas yang diajar, sekiranya kelas aras rendah BBM yang digunakan tidak boleh membahayakan murid. Penggunaan BBM yang mudah diperolehi, ceria digunakan seperti contoh blok kayu berwarna serta Interaktif dan menarik lebih kepada penglibatan deria sentuhan, penglihatan, dan pendengaran.". (PKG 5)

Bagi PKG 3, menggunakan cara mengkaji beberapa cara sebelum melakukan pengajaran dijadikan sebagai penentuan bagi penggunaan BBM yang sesuai untuk sesuatu pengajaran.

"Sebelum menjalankan sesi pengajaran, saya akan mengkaji beberapa cara bagi murid faham pengajaran saya terutama dalam operasi darab. Saya akan ajar mereka cara yang mudah ingat operasi darab. Murid sudah faham pada pengajaran atau tidak. Kita perlu berusaha mencari formula mudah supaya murid tidak takut apabila mendengar sifir atau darab.”. (PKG 3)

\section{Meneroka jenis bahan bantu mengajar yang digunakan oleh guru pendidikan khas}

Analisis bagi objektif kajian 2, iaitu meneroka jenis bahan bantu mengajar yang digunakan dalam meningkatkan kemahiran matematik operasi darab. Penggunaan 2 jenis BBM yang biasa digunakan oleh peserta kajian iaitu penggunaan bahan maujud serta penggunaan peranti elektronik.

\section{Bahan bantu mengajar}

Hasil daripada dapatan temu bual yang telah transkripkan menyatakan PKG2, PKG 3, PKG 4 dan PKG 5 menggunakan bahan maujud yang mudah dan senang diperoleh di kawasan sekolah.

"Saya menggunakan buku sifir dan bahan-bahan maujud seperti guli, kotak atau apa-apa sahaja bahan yang digunakan untuk menyelesaikan pengajaran darab pada tahap rendah". (PKG 2)

"Saya menggunakan kaedah tulang ikan dalam menyelesaikan operasi darab mudah. Kaedah mudah difahami serta dapat menarik minat murid untuk seronok mempelajari operasi darab". (PKG 3)

"Saya menggunakan kaedah Jadual Sistem Darab Pantas serta bahan-bahan maujud yang mudah diperolehi. Saya juga menggunakan Jadual Sifir bagi memudahkan murid menghafal Sentiasa ulang sifir dan sentiasa ingatkan cara pengiraan darab.". (PKG 4)

"Cara meningkatkan kefahaman melalui beberapa langkah iaitu uji minda untuk mengesan tahap keupayaan, soal jawab dan aktiviti berkumpulan amat membantu. Satu kumpulan melibatkan 2 atau 3 ahli sahaja. Saya juga banyak menggunakan bahan maujud dan menghafal sifir. Sifir yang dihafal dalam bentuk lagu dan saya akan membuat latihan secara berulang untuk memberikan kefahaman dan ingatan pada murid.". (PKG 5)

Seterusnya bagi PKG 1 akan menggunakan bahan-bahan elektronik atau bukan elektronik dalam sesi pengajaran dan pembelajaran mereka mengikut situasi dan masa.

“ Bahan-bahan yang saya gunakan terdiri daripada bahan elektronik dan bahan bukan elektronik. Selain daripada itu, Penggunaan pelbagai deria murid dan kaedah bagi menarik minat murid dalam mempelajari operasi darab" (PKG 1). 


\section{Perbincangan}

Secara keseluruhan, dapatan daripada hasil temu bual ke atas peserta kajian menunjukkan guru menggunakan pelbagai jenis bahan bantu mengajar dalam sesi pengajaran dan pembelajaran. Majoriti guru dapat menjelaskan dengan tepat fungsi bahan bantu mengajar sebagai satu bahan atau alat pemudah cara yang membantu guru dalam memberikan kefahaman yang jelas tentang operasi darb dikalangan murid MBK pembelajaran. Penggunaan bahan bantu mengajar yang bersesuaian, menarik dan mudah didapati, membantu murid memahami dan fokus dalam pengajaran di dalam kelas. Guru juga perlu kreatif dalam membina serta mengolah BBM, ini adalah kerana penggunaan bahan yang kurang menarik akan menyebabkan murid kurang fokus dalam pembelajaran (Isa \& Ma'arof, 2018). Oleh kerana itu, guru perlu melakukan persediaan yang mantap daripada isi kandungan pengajaran, aktiviti dan BBM yang bersesuaian sebelum memulakan kelas. Perancangan dan persedian yang rapi daripada kesemua peserta kajian sebelum bermulanya sesi pengajaran dan pembelajaran memberikan persediaan kepada guru. Penyataan ini disokong oleh Ali et al. (2019) dan Nadzri (2017) yang menyatakan perancangan dan persediaan yang rapi perlu bagi seseorang guru sebelum proses pengajaran dan pembelajaran bagi mendapatkan hasil dan kualiti sesuatu pengajaran tercapai.

Tahap penguasaan murid juga menjadi faktor penentuan dalam pemilihan penggunaan bahan bantu mengajar operasi darab. Bagi menyelesaikan operasi darab yang mudah dan tahap penguasaan murid yang rendah, penggunaan blok kayu berwarna, guli digunakan bagi sesi pengajaran dan pembelajaran. Selain daripada itu cara hafalan sifir berlagu digunakan oleh guru agar murid mudah mengingati sifir yang diajar. Penggunaan bahan maujud membolehkan murid memegang, merasa dan memberikan pengalaman kepada mereka. Berlainan pula murid yang mempunyai tahap penguasaan yang tinggi penggunaan jadual sistem darab mudah, kaedah tulang ikan dan petak sifir menjadi pilihan guru untuk memberikan kefahaman kepada murid.

Penggunaan kaedah ini lebih mudah difahami oleh murid seterusnya menimbulkan minat murid dengan mata pelajaran matematik. Setiap guru perlu mempunyai pengetahuan dan sokongan sepenuhnya dalam pembelajaran MBK pembelajaran yang terdiri daripada pelbagai ketidakupayaan. Penggunaan pelbagai strategi yang berbeza serta kesesuaian dengan kemampuan dan tahap setiap murid (Norfishah, 2016). Selain daripada itu penggunaan bahan bantu mengajar yang terdiri daripada bahan elektronik juga mampu memberikan keseronokan dan minat murid dalam pengajaran operasi darab. Penggunaan kuiz yang dilakukan secara atas talian menarik minat murid untuk mencuba sesuatu yang baru. Gabungan elemen warna, bentuk dan muzik yang boleh dibangunkan oleh guru bagi pengajaran sesuatu topik mampu dilakukan dengan menggunakan bahan elektronik.

\section{Kesimpulan}

Kajian ini membuktikan penggunaan bahan bantu mengajar (BBM) dapat meningkatkan kefahaman murid dalam kemahiran matematik terutama dalam operasi darab. Persediaan yang rapi oleh guru-guru sebelum sesi pengajaran dan pembelajaran dan penggunaan BBM yang sesuai dengan tahap penguasaan murid mampu memberikan impak yang tinggi kepada murid. Peranan guru sebagai pendidik dan pemudah cara membantu murid dalam kefahaman operasi darab dan seterusnya akan mereka gunakan dalam kehidupan seharian. Implikasi daripada kajian yang telah dijalankan telah membuktikan terdapat pelbagai bahan bantu mengajar yang digunakan bagi meningkatkan kefahaman murid dalam operasi darab. Penggunaan BBM yang sesuai memberikan MBK pembelajaran pengalaman seterusnya memahami konsep darab dengan betul. Secara tidak langsung menimbulkan minat MBK dalam mata pelajaran matematik. Cadangan untuk kajian di masa akan datang supaya kajian dijalankan bagi meneroka lebih mendalam keberkesanan dalam penggunaan bahan bantu mengajar yang digunakan oleh guru-guru bagi memberikan kefahaman kepada murid MBK pembelajaran. Kajian ini dilakukan dijalankan di empat buah sekolah di sekitar daerah pudu dan tidak menggambarkan keseluruhan guru di Kuala Lumpur. 


\section{Rujukan}

Ali, S. K. S., Rauf, P. A., \& Salimin, N. 2017. Hubungan antara pengalaman mengajar dan perancangan pengajaran dalam kalangan guru pendidikan jasmani tingkatan 4. International Journal of Education, Psychology and Counseling, 2(6): 268-277 [21 Disember 2021].

Chua Yan Piaw. 2014. Kaedah Pengkajian. Edisi Kedua. Kuala Lumpur: McGraw-Hill Higher Education.

Hanifah Mahat, Satryani Arshad, Yazid Saleh, Kadaruddin Aiyub, Mohmadisa Hashim, Nasir Nayan. 2020. Penggunaan dan penerimaan bahan bantu mengajar multimedia terhadap keberkesanan pembelajaran geografi. GEOGRAFIA OnlineTM Malaysian Journal of Society and Space, 16(3): 219-234. [10 Oktober 2021].

Hayazi Mohd. Yasin. 2008. Penggunaan alat bantu mengajar dalam kalangan guru sekolah teknik. Kertas Projek Sarjana Pendidikan. Fakulti Pendidikan, Universiti Teknologi. [19 Oktober 2021].

Isa, N. S., \& Ma'arof, N. N. M. I. 2018. Keberkesanan penggunaan grafik berkomputer sebagai alat bahan bantu mengajar dalam kalangan pelajar reka bentuk dan teknologi. Sains Humanika, 10(33): 81-87 [10 Oktober 2021].

Jasmi, K. A., Ilias, M. F., Tamuri, A. H. \& Mohd Hamzah, M. I. 2011. Amalan Penggunaan Bahan Bantu Mengajar dalam Kalangan Guru Cemerlang Pendidikan Islam Sekolah Menengah di Malaysia. Journal of Islamic and Arabic Education, 3(1): 59-74. [14 November 2021].

Jeffery Tikok. 2018. Sikap dan jantina guru bahasa melayu sekolah rendah daerah serian terhadap pemilihan bahan bantu mengajar. Jurnal Pendidikan Bahasa Melayu - Jpbm (Malay Language Education Journal - Mylej), 8 (1): 13-21. [14 November 2021].

Mohd Rino Mohd Johari. 2019. Keberkesanan penggunaan i-koam dalam matematik dan impak terhadap tingkahlaku introvert murid pemulihan khas. Seminar Antarabangsa Isu-Isu Pendidikan (Ispen 2019 || Eisbn 978-967-2122-77-7). Auditorium Dr. Zainuddin Jaafar, Kuis. [25 November 2021].

Mohd Zuri Ghani \& Aznan Che Ahmad. 2012. Kaedah dan Strategi Pengajaran Kanak-Kanak Berkeperluan Khas. Cetakan Semula. Pulau Pinang: Penerbit Universiti Sains Malaysia. [25 November 2021].

Musa, N. E., \& Mohamad, M. H. 2013. Keberkesanan Penggunaan Alat Bahan Bantu Mengajar Dalam Pelaksanaan Kursus Sains Kejuruteraan di Kalangan Pelajar Diploma Kejuruteraan di Politeknik Tuanku Sultanah Bahiyah. Politeknik Tuanku Sultanah Bahiyah, 1(1): 223-230. [25 November 2021].

Nadzri, N. F. 2017. Kualiti amalan guru dalam pengajaran dan pembelajaran Bahasa Melayu di MRSM (Master thesis). Fakulti Bahasa dan Komunikasi, Universiti Pendidikan Sultan Idris. [23 November 2021].

Norfarizah Mohd Bakhir, Mohd Zazril \& Ikhmal Zamri. 2019. Penggunaan bahan bantu mengajar berasaskan papan pelbagai sentuh untuk pembelajaran sains tahun tiga. Journal on technical and vocational education (jtve), 4 (3) :Special edition nasco (2019). [15 November 2021].

Norfishah Mat Rabi. 2016. Transformasi pendidikan murid kurang upaya. Tanjong Malim: Penerbit Universiti Pendidikan Sultan Idris. [05 November 2021].

Noor Azimah Binti Abdul Ghani. 2016. Pembangunan Set Lengkap ASK (Algebra Story Kit) Membantu PdP Dalam Matematik. Conference Proceeding: 2nd International Conference On Creative Media, Design \& Technology (REKA2016) [05 November 201]. 